\title{
Multimedia Teaching Platform Design for Urban Planning Course Based on Information Entropy
}

\author{
https://doi.org/10.3991/ijet.v12i07.7213 \\ Xiaopeng Jing \\ School of Architecture, Chang'an University, Xi'an, China \\ jingxp1207@163.com
}

\begin{abstract}
The information entropy theory involves such important concepts as the amount of information and information entropy, and it is widely applied in educational field. At present, teaching contents of Urban Planning are dull, and teaching methods and means are single. For such characteristics, information entropy theory and MP5 technology were introduced in multimedia teaching platform design. The new teaching platform was designed from 4 aspects: video module, audio module, network module and electronic module. Since information entropy theory can make information quantified, the teaching contents can be visualized, and teaching interestingness can improve. Meanwhile, because MP5 has such characteristics as diversified technological functions and use convenience, it can enhance multimedia teaching effect. The new teaching platform can let the teaching contents more vivid and visual, motivate students' learning initiative and promote teaching quality.
\end{abstract}

Keywords-Information entropy, multimedia teaching, urban planning, MP5

\section{$1 \quad$ Introduction}

With rapid economic development, urban construction scale has become larger and larger. Correspondingly, urban planning discipline also has become the major development object in recent years. So far, over 100 universities in China have set up urban planning discipline which involves multiple aspects including urban social economy, architectural engineering, landscape environment and planning technology. Various universities mostly adopt their own teaching materials, and traditional multimedia teaching is the main teaching means [1]. In terms of teaching research on Urban Planning course, some western developed countries summarize the teaching objective, i.e. to cultivate students' professionalization, diversification and knowledge integration ability [2]. In China, the researches mostly remain at the macroscopic level and fail to involve the specific teaching method. Only few articles study the specific problems in the teaching process such as course arrangement and teaching material update. There is short of effective teaching method research [3]. 


\section{Research progress}

Bai et al. [4] constructed an experimental course teaching platform for Urban Planning course, proposed the application of GIS technology and experiment teaching decision analysis model in multimedia teaching, and analyzed the specific application of GIS in Urban Planning experiment teaching from general planning and detailed planning. The results show that the new teaching platform has a good effect on the education of urban planning major. Ezennia et al. applied digital architectural design studio. Hence, based on the teaching objective of making the best of digital multimedia in the design process, this study aims to find out the most suitable year in the undergraduate program and the most suitable state in the design process for digital multimedia application in architectural education. The results show that the application of digital multimedia in architecture design studios would assist instructors in better understanding their courses [5]. In general, as a developing county, China pointes out in the researches that, the teaching effect of modern technology in Urban Planning course is not ideal, and the specific problems are reflected in two aspects. On the one hand, the teaching method is mainly traditional multimedia teaching. Such teaching mode mainly depends on the multimedia classroom. In the early stage, the investment in multimedia classrooms is high, and the maintenance cost in the later stage is also high. Thus, the number of multimedia classrooms is small in universities, which limits the use frequency of students. The multimedia classroom is crowded, and students' learning environment is not very good. Besides, the interactions between the teacher and students are few [6]. The opening time for multimedia classrooms is limited, and students cannot use multimedia equipment anytime. Meanwhile, the hardware of multimedia classrooms concentrates, which will generate certain radiation. This is adverse to students' health [7]. On the other hand, in multimedia classroom teaching process, some teachers pay much attention to explanation of multimedia courseware, ignore interactions with students and fail to motivate students' initiative [8]. In addition, since the limit of classroom time, students cannot view the key and difficult contents repeatedly. Some video contents cannot be played due to time limit, which influences the teaching effect. Moreover, listening to the teacher and understanding of teaching content are affected, because students take notes in classroom [9].

For the above situations, this paper information entropy theory [10] and MP5 technology are creatively introduced to improve Urban Planning teaching in this paper. Information entropy theory which was put forward by Shannon is mainly used to quantify information and then describe the amount of information in each piece of information. Information entropy theory may be used to express teaching contents more visually. For example, land use condition in urban planning can be reflected through data and tables after information entropy processing so that students can understand the teaching content more easily. MP5 (MPEG Layer 5) is a kind of electronic products. It can be used to watch TV and video and play audio/video files of multiple formats, with the functions of picture and e-book reaching. It not just has small size, but also low cost. Students can carry it and view multimedia courseware 
anytime. Due to the characteristics of low technical cost, portability and repeated playing, MP5 can make up for defects of multimedia teaching [11].

\section{Model analysis}

The new multimedia teaching platform design is mainly divided into two parts. In Part I, multimedia teaching courseware is produced to make multimedia courseware content more beneficial to teaching and students' understanding. In Part II, MP5 technology is applied to complete software and hardware design of the platform. In Part I, information entropy theory is mainly applied in teaching content innovation. To be specific, information entropy analysis is carried out for the content of Urban Planning course, and the abstract and complex content is digitalized. Meanwhile, in course teaching process, information entropy theory is used to guide students to expand unknown knowledge by applying the existing knowledge so as to enhance teaching interaction and cultivate students' creative thinking.

The concept of information entropy was used by Shannon to describe uncertainty of information source. According to Shannon's information entropy formula, for any random variable $\mathrm{X}$, its information entropy is defined as follows, with the unit of bit:

$$
\left.H(X)=-\sum x \varepsilon X P(x) \log P(x)\right)
$$

The information amount of the above random variable is

$$
H=-(p 1 \log p 1+p 2 \log p 2+\ldots p 32 \log p 32)
$$

There are many contents of Urban Planning course. Land use situation in urban planning is an abstract and difficult teaching content. Since land use situations are diversified, it is very hard to judge according to certain standards on the whole. But in such situation, information entropy theory may be used for quantitative analysis of complex situations. Land use situation in urban planning may be used as an example to express the application of information entropy theory. We suppose that a city owns the construction lands with the total area of S. According to requirements of urban planning, these construction lands are classified into $m$ types according to the purposes, and the area of each type of land is P. First of all, the ratio of various lands with different purposes in the whole construction land should be figured out, i.e. the occurrence possibility of the land with the area of in all land types, expressed as.

$$
P_{i}=\frac{S_{i}}{S}, \sum_{i=1}^{m} P_{i}=1
$$

In accordance with the information entropy formula, information entropy function of land use situation is

$$
H=-\sum_{i=1}^{m} P_{i} \ln P_{i}
$$


$\mathrm{H}$ is information entropy. It can be seen from Formula 2 that, information entropy value may be used to judge land use situation. The higher entropy value means there are more lands with different purposes, and the area difference between the lands with different purposes is smaller. In other words, land distribution is more balanced. A maximum value exists in Formula 2. When the area of all $\mathrm{m}$ lands with different purposes is same, the entropy value is the maximum. This is also the most ideal situation of urban land use.

Based on this principle, specific urban land use situation may be analyzed. For example, the statistics of land use situations of Xi'an City from 1959 to 2016 is as follows. The information entropy $\mathrm{H}$ of annual land use situation is calculated according to Formula 2. The results are made into the demonstration diagram, as shown in Fig.1: Interface 1.

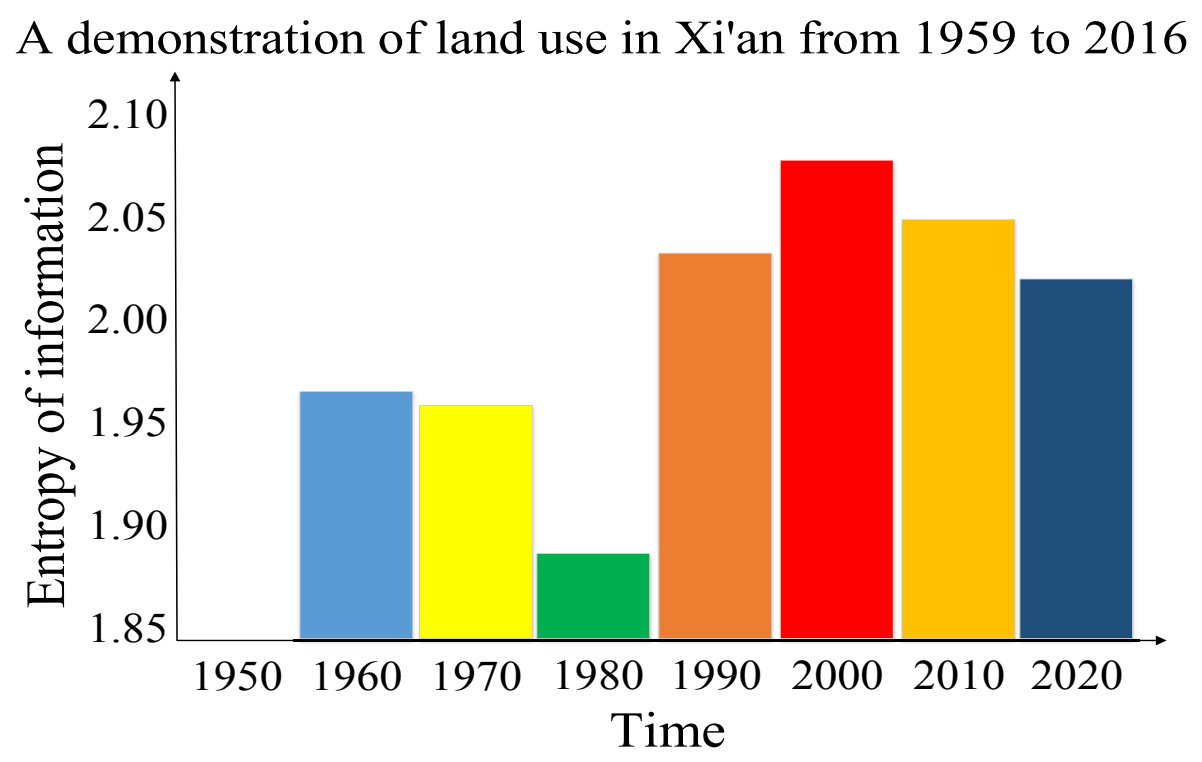

Fig. 1. Entropy value demonstration diagram of land use situation in Xi' an in 1959-2016

We can see from Fig. 1 that, land use situation in Xi' an in recent 50 years is divided into two stages. In the first stage (1959-1979), the entropy value continued to decrease, and the change range was small. This indicates the construction land situation is stable. The reason for the decrease is that the land for public facilities, roads and squares increased. This breaks land use balance. In the second stage (1979-2004), the entropy value started to rise sharply and then grew slowly. After 2004, the entropy value started to fall after the rise. This indicates that the stage of 1979-2004 is the upheaval stage of construction land use in Xi'an. The land for transportation, the land for roads and squares and residential land changed a lot. This shows the city is expanding and developing. On the whole, land diversity index of Xi' an is high, and land use types are rich. 
Based on the above, the application of information entropy theory in urban planning land use situation can visually reflect the results through data and tables. This can help students absorb and master the knowledge. Similarly, some other contents of urban Planning course can be integrated again in such way to make multimedia courses with a better teaching effect. According to the multimedia courses, teachers can impart teaching contents more flexibly and vividly. For instance, during evaluating urban planning design of a city, the uncertainty of this event is high, and information occurrence probability is small before the evaluation standard is established. Relatively speaking, the attraction of this event is small, and information dissemination range is narrow, besides, the information entropy value is large. The teacher guides students to discuss and establishes various evaluation standards through data and case analysis. The amount of information will be ranked in ascending order, and information occurrence probability becomes large. The rise in the information amount can also attract others' interest. The communication range expands and information entropy increases. In the whole discussion process, students gradually infer an abstract evaluation problem according to the questions proposed by the teacher and the information entropy formula, gain the conclusions and analyze whether their results conform to the actual conditions. This is a teaching process of guiding students to improve rich association and reasonable inferring, and it can enhance students' innovation ability. Field demonstration of entropy of land use in Multimedia Courses can see from figure 2.

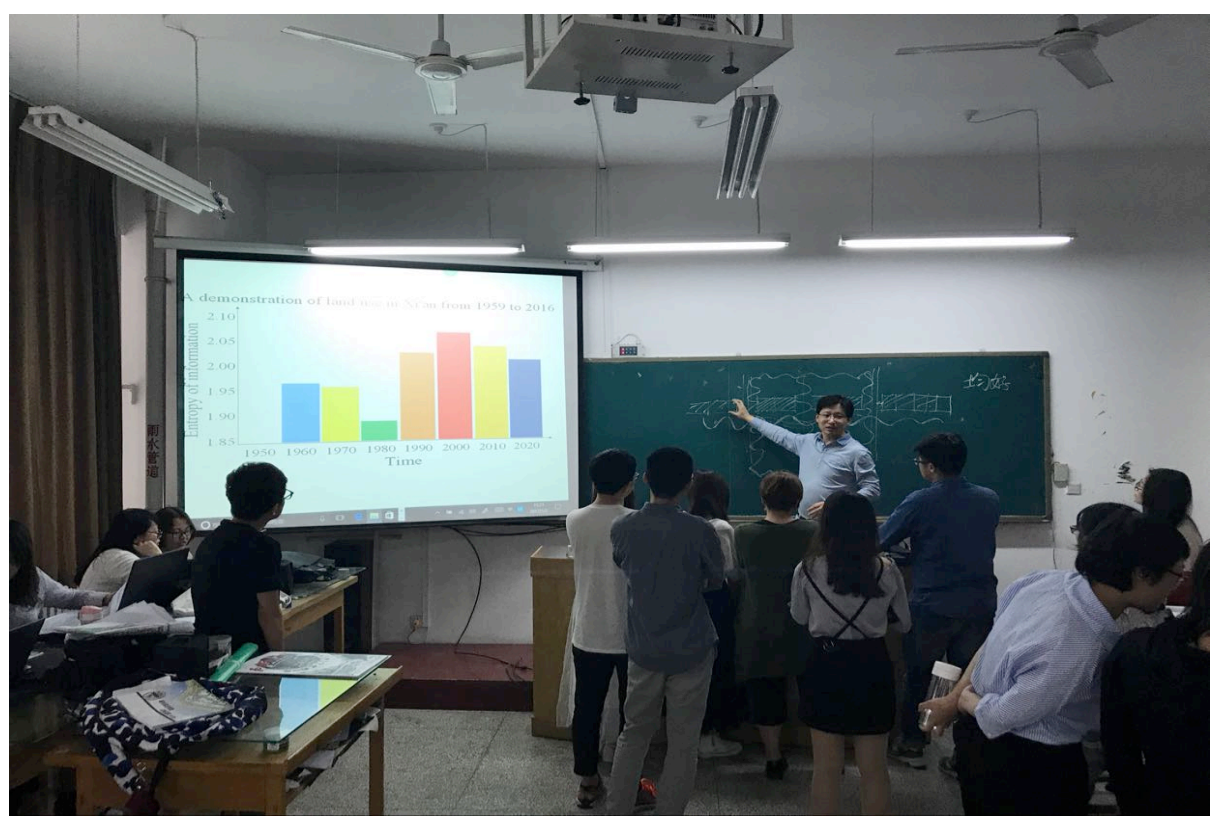

Fig. 2. Teaching display of information entropy in Multimedia Courses 


\section{Design of multimedia teaching platform}

Since traditional multimedia teaching has many defects, MP5 technology is applied in this paper to design multimedia teaching platform. The main reasons are as follows. (1) MP5 can recognize multiple videos and image texts such as MP4 and 3GP. (2) MP5 can play the videos with high-quality pictures and sound. With small size, MP5 is easy to carry. (3) Learning flexibility is high. Students may freely choose learning contents, time and environment. (4) Classroom contents can be stored in the hard disk by applying storage function of MP5, which can save the time for taking notes and help students listen to the teacher in class. (5) Teachers' repeated work can decrease, and teachers' workload can decrease.

In accordance with multimedia teaching demand, the new multimedia teaching platform needs four functions, including video playing, audio playing, text reading and webpage browsing. Thus, MP5 technology also contains four sub-modules in terms of system structure. The design mode adopts Launcher part of Android system. Launcher.xml controls the file layout and structure. Fig. 2 shows the overall structure diagram of the system.

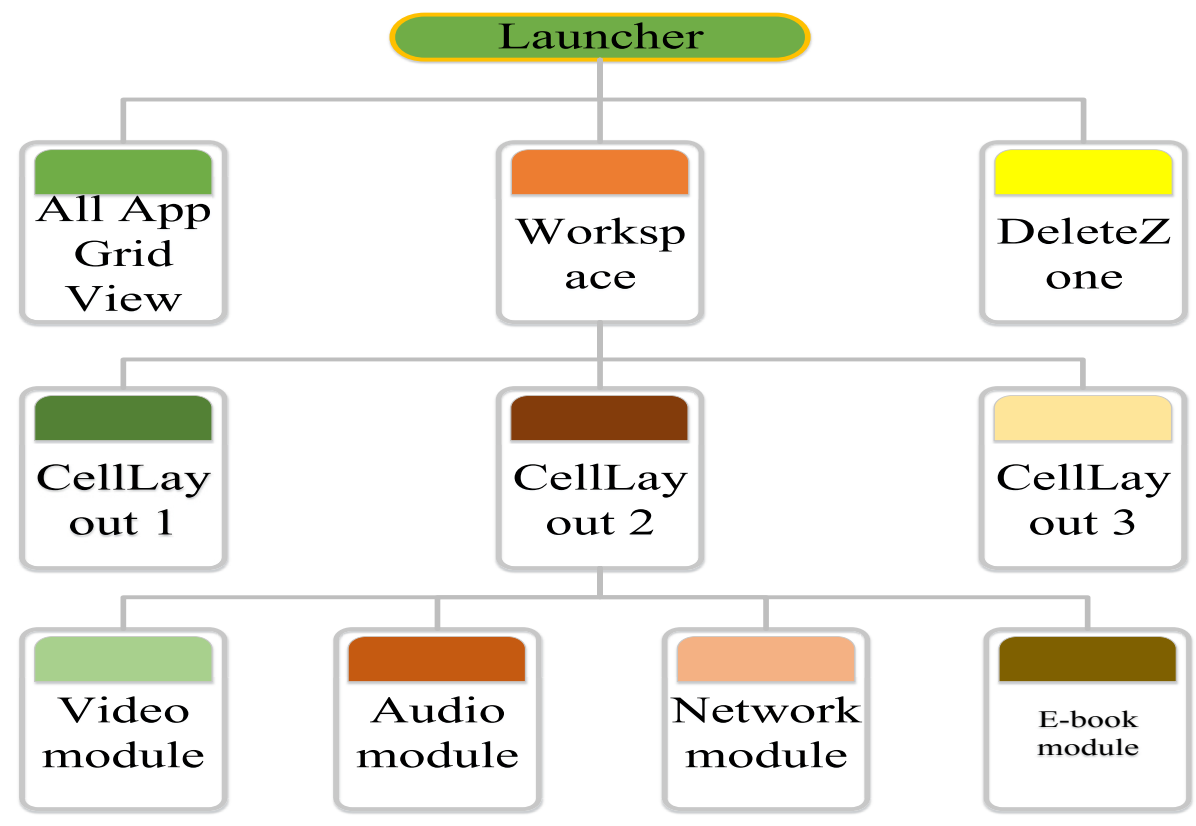

Fig. 3. Overall structure diagram of the system

\subsection{Video module design}

Video module aims to implement video playing control. MoviePage.xml file controls the layout structure. It includes three controls: background circular screen, turntable and tray. Fig. 3 shows the structure diagram of video module. 


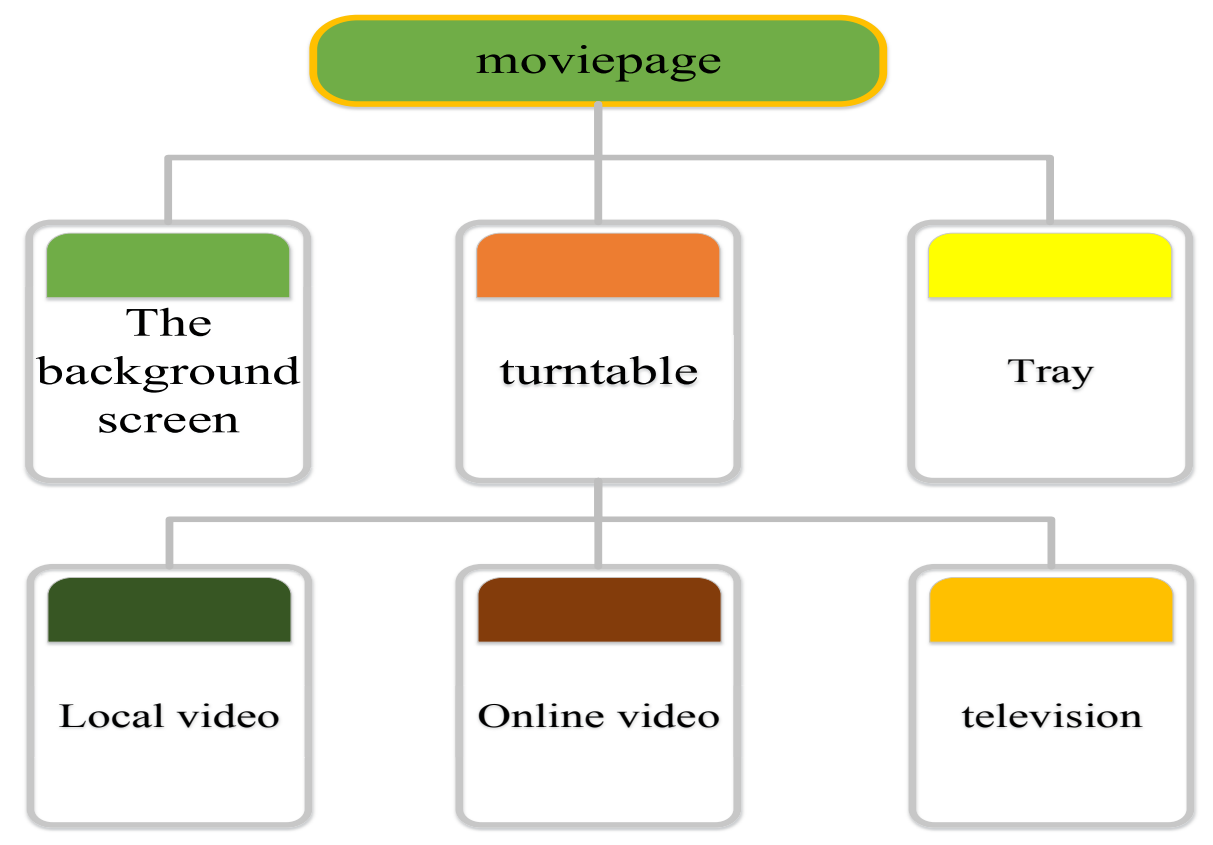

Fig. 4. Structure diagram of video module

Background circular screen: it acts as the background of the whole module. Whenever a video is played, background circular screen will carry out screenshot for the video and save the screenshot as playing history of the video. Users can browse playing history of each video through sliding the button. Meanwhile, the background also has click function. In other words, users can start up associated video files through clicking the screenshot.

Tray: it is used to store application programs. Application programs stored in the tray can make sure they will not be lost after the equipment restarts. The detailed method is as follows: the database is used to import the application program in the database for keeping. There are the trays in several modules, and these trays reach the purpose of data sharing through using the same tables to store data.

Turntable: it is mainly used to change over to browse local video, online video and TV. Video files kept in the hard disk will be displayed in the list form through system scanning. Then, users can choose the videos to watch through sliding the list. The listing form of these videos adopts GridView. The multimedia interface of urban planning course based on information entropy is shown in figure 5 .

\subsection{Audio module design}

The main function of audio module is to implement audio playing control. MusicPage.xml controls the layout structure. This module includes turntable, tray and mini audio player etc. Fig. 6 shows the structure diagram of audio module. 


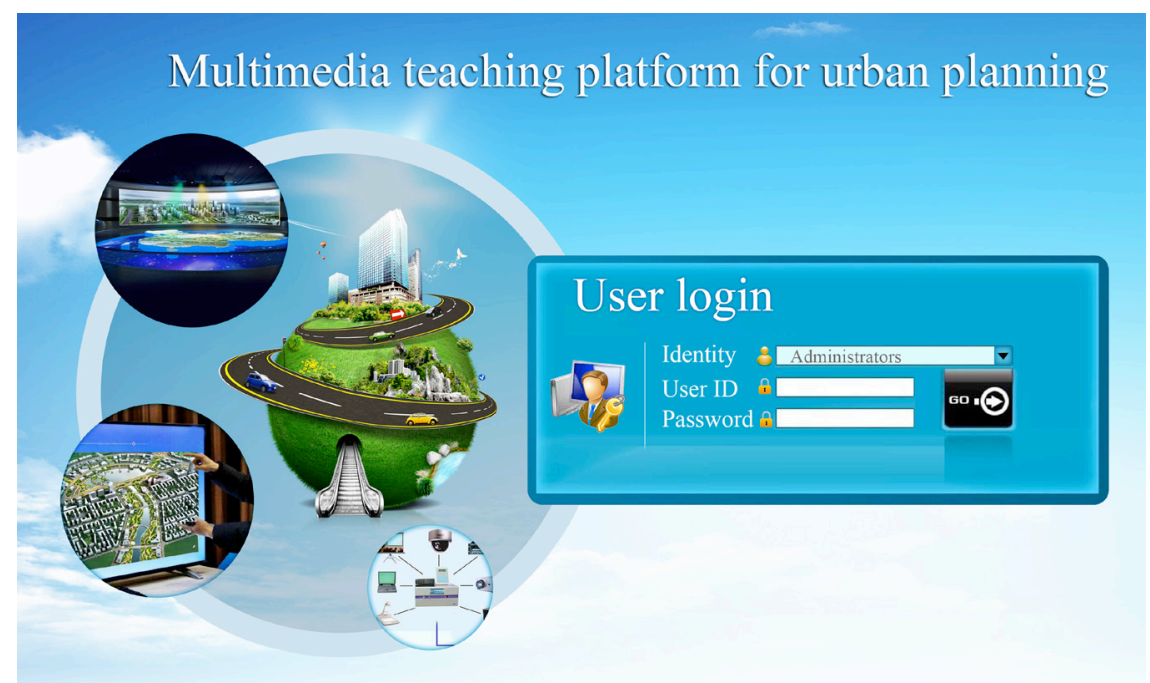

Fig. 5. Multimedia interface of urban planning course based on information entropy principle

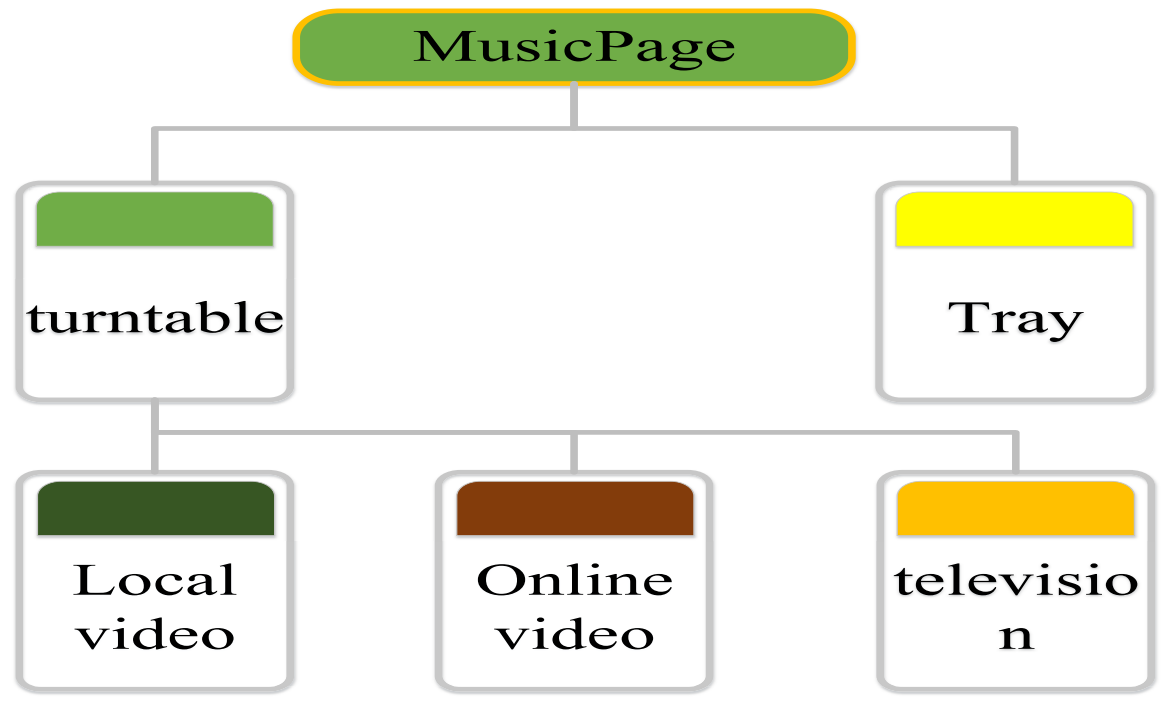

Fig. 6. Structure diagram of audio module

The tray and turntable controls of audio module are same with those of video module. Here, local audio, online audio and TV are mainly introduced.

Local audio: it is used to display audio files stored in the equipment. The method is as follows: system scanning is adopted to check whether the files of audio format exist. If the files exist, these files are displayed in the list form. Audio playing mode adopts backstage playing mode. The advantage of such mode is that even if the module quits, the audio can continue to be played. Audio playing control adopts mini audio player. 
Online audio and TV: the two controls are used to watch TV and listen to music under the condition of networking. They are stored in the tray in the form of application program.

\subsection{Network module design}

Network module provides users with the function of browsing webpage online. NetworkPage.xml controls the layout structure. Fig.7 shows the structure diagram of network module.

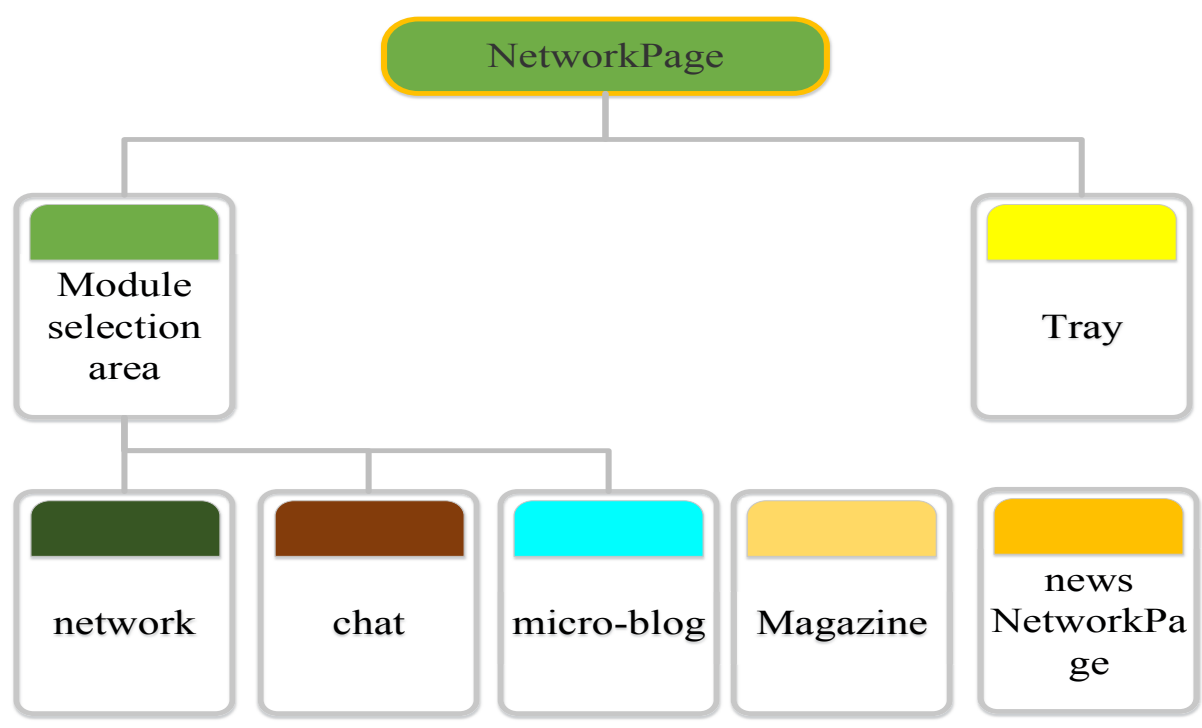

Fig. 7. Structure diagram of network module

We can see from Fig.5 that, the whole module is divided into five parts according to the functions: network, chatting, microblog, magazine and news. The four submodules (chatting, microblog, magazine and news) adopt the form of application box, similar to online video and TV in the video module. Network sub-module owns the function of saving webpage browsing history, and the webpage browsing history is kept through webpage screenshot. Users may input the website or click the screenshot to browse webpage.

\subsection{E-book module design}

E-book module mainly provides users with e-book reaching function. BookPage.xml controls the layout structure. The module manly includes two parts: book reading and book management. Fig. 6 shows the structure diagram of e-book module. 


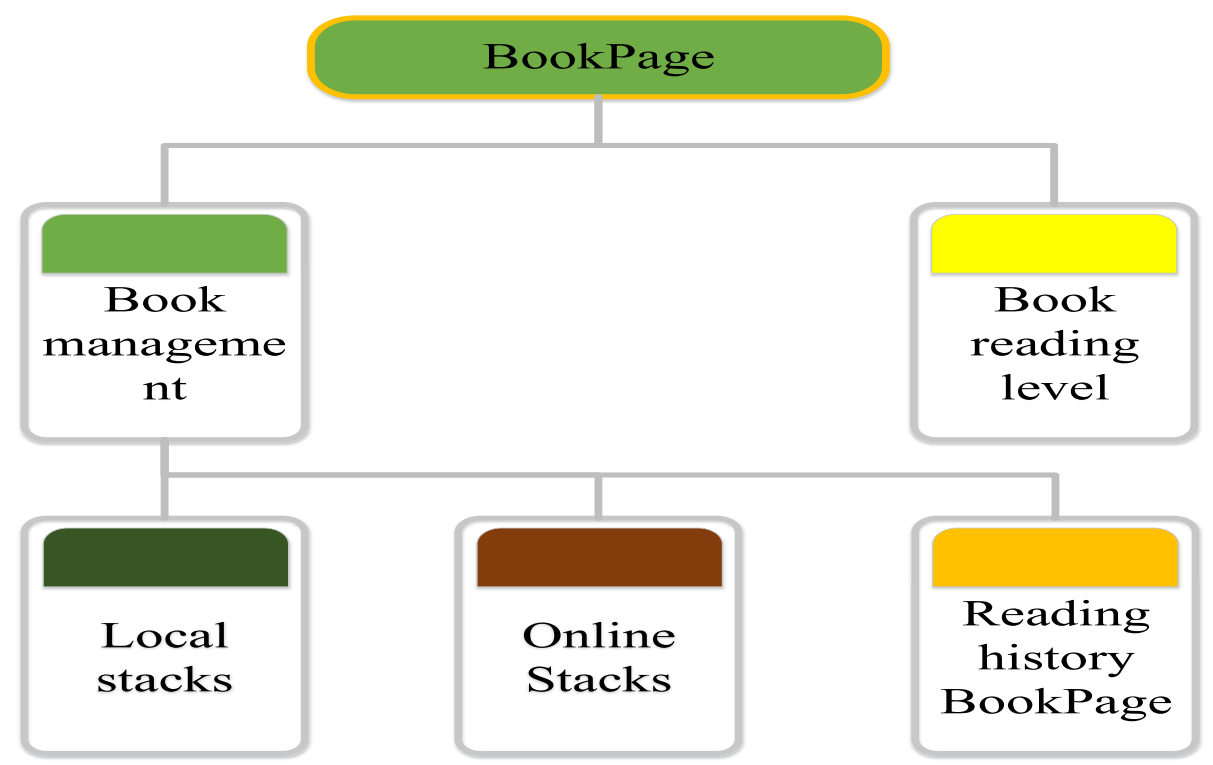

Fig. 8. Structure diagram of e-book module

Book management layer is divided into three parts: local book library, online book library and reading history. Local book library is mainly used to display the e-book files stored in the equipment. Whenever the e-book are imported in the equipment and the e-book is opened the first time, the system will decode according to the format of e-book, display e-book content and display the book title in the local book library. Ebook catalogue displayed in online book library is just the network link of e-book. After users click the e-book title, corresponding webpage can pop out. Reading history is mainly used to save reading history records of e-book. The saving form is to display the cover of each e-book. Users may click the cover of e-book to check recent e-book reading position. The main function of book reading layer is to display the ebook content on the screen through decoding. Besides, it also has the function of page turning and skipping to other pages.

\subsection{Effect analysis}

To test the teaching effect of the new mode, the students of urban planning major at Chang'an University in were selected as the objects of study. The selected course was Urban Master Planning. There were 220 sophomores of urban planning major at the university. The 220 students were classified into Class 1 and Class 2 averagely. Traditional multimedia teaching platform was applied for Class 1, while new multimedia teaching platform was applied for Class 2 . Both classes were taught for 1 year, and professional course examination was implemented at the end of the year. Besides, the examination scores were recorded. Then, the examination scores of both classes were compared. The detailed score statistics is shown in Table 1 and Table 2. 
Table 1. Statistical table of examination scores in Class 1

\begin{tabular}{|l|c|c|c|c|}
\hline \multicolumn{1}{|c|}{ Examination content (Class 1) } & Excellent (No.) & Good (No.) & Pass (No.) & Fail (No.) \\
\hline Detailed Urban Planning Design & 11 & 32 & 51 & 16 \\
\hline Garden Architecture Design & 12 & 34 & 53 & 11 \\
\hline Urban Road and Traffic & 9 & 38 & 48 & 15 \\
\hline Fundamentals of Urban Planning & 8 & 40 & 49 & 13 \\
\hline Urban Planning Administration and Laws & 15 & 37 & 44 & 14 \\
\hline
\end{tabular}

Table 2. Statistical table of examination scores in Class 2

\begin{tabular}{|l|c|c|c|c|}
\hline \multicolumn{1}{|c|}{ Examination content (Class 2) } & Excellent (No.) & Good (No.) & Pass (No.) & Fail (No.) \\
\hline Detailed Urban Planning Design & 15 & 41 & 54 & 0 \\
\hline Garden Architecture Design & 17 & 52 & 39 & 2 \\
\hline Urban Road and Traffic & 13 & 59 & 38 & 0 \\
\hline Fundamentals of Urban Planning & 14 & 61 & 34 & 1 \\
\hline Urban Planning Administration and Laws & 22 & 54 & 33 & 1 \\
\hline
\end{tabular}

Based on the above two tables, the number of excellent and good students in Class 2 increases significantly. The score growth of Fundamentals of Urban Planning is most obvious. This indicates the new multimedia teaching platform greatly improves students' professional course scores. In particular, the improvement effect is obvious for the courses with abstract and difficult contents. Moreover, the questionnaire survey was conducted for teachers and students in Class 2. The results show that, students generally express the new multimedia courseware content is easier to understand and grasp, and the classroom atmosphere is more active. The application of MP5 player significantly enhances learning interest. More than 98\% of students expressed they refer to MP5 in learning. The teachers said, after MP5 is applied in teaching, teaching burden was lightened greatly, and it was no longer necessary to explain much knowledge repeatedly.

\section{Conclusions}

Urban Planning is a theoretical course with strong expertise. The course mainly teaches students to carry out general deployment in order to achieve the development and construction objective in a region. In the actual teaching process, we have found that, the multimedia teaching platform for Urban Planning course based on information entropy theory can embody the teaching advantages of large information amount, dynamics and third dimension in the teaching process. Especially when students understand building size and spatial scale, the new the multimedia teaching platform presents a better teaching effect, relative to single traditional teaching media source combination. The performance of Class 2 is significantly better than that of Class 1 . On the one hand, information entropy theory is applied in this research. During teaching contents of some chapters such as classified expression of urban administrative boundary and entity boundary, the concept of city entity may be introduced in 
classroom. In addition, information entropy value of land use result can be used to objectively reflect the order degree of land use system in a region. On the other hand, after the teacher demonstrates the formula in classroom, students may play classroom teaching content repeatedly via MP5 and reach the learning effect of auxiliary explanation of knowledge points after class. Finally, it can help students effectively absorb new knowledge and improve learning interest. Besides, students' knowledge mastery degree will also improve.

In one word, based on the development of modern information technology, many kinds of media software well assist Urban Planning teaching. Modern media software plays an irreplaceable role. But in the future teaching process, teachers should combine teaching contents to rationally apply advanced multimedia software. Meanwhile, teachers should guide students through properly setting teaching questions, visually process design problems, and directly point out students' shortcomings so as to avoid students' fuzzy cognition in complex space treatment and improve their space design ability.

\section{Acknowledgment}

This work was supported in part by the Chang'an University 2017 graduate education teaching reform project.

\section{$7 \quad$ References}

[1] Li, N., Gong, H.F. Exploration of Architectural Design Teaching Based on Applied Talents Training and its Practice, Anhui Architecture, 2012, vol. 19(1), pp. 85-87.

[2] Duan, D.G. Public Policy Literacy Development in Basic Course Teaching of Urban Planning[J]. China City Planning Review, 2015, vol. 20(3), pp. 36-40.

[3] Yuan, Y., Wang, L.S., Ma, M.C. Research on modular construction teaching mode of Applied Talents Training, Sichuan Building Materials, 2016, vol. 42(5), pp. 221-223.

[4] Bai, Z.L., Zhang, X.R. Application of GIS Spatial Analysis in Experimental Teaching of Urban Planning, Research and Exploration in Laboratory, 2013, vol. 32(10), pp. 387-390.

[5] Ezennia, I.S., Uwajeh, P.C., Agbonome, P.C., et al. The benefits of digital multimedia as a teaching and learning aid in architectural design studios, 2016, vol. 8(9), pp. 39210-39217.

[6] Liu, J., Yang, Y.N. Teaching reform and practice of architectural technology courses, Shanxi Architecture, 2015, vol. 41(9), pp. 237-238.

[7] Chen, X., Zhou, Z.W., Zhu, Y. Development and Enlightenment of Research-Oriented Design Teaching in Architectural Education, Architecture \& Culture, 2015, vol. 8, pp. 146147.

[8] Wu, W. How to Balance Technology and Art?A Study of Applying Green Design in Building Technology Courses, South Architecture, 2016, vol. 5, pp. 124-127.

[9] Hong, Z., Gu, C.L., Gu, L.W., et al. The evaluation of tourism destination competitiveness by TOPSIS \& information entropy - a case in the Yangtze River Delta of China, Tourism Management, 2011, vol. 32(2), pp. 443-451. https://doi.org/10.1016/j.tourman.2010. $\underline{02.007}$ 
[10] Carlson, C., Arnedo, V., Cahill, M., et al. Detecting nocturnal convulsions: efficacy of the MP5 monitor, Seizure European Journal of Epilepsy, 2009, vol. 18(3), pp. 225-227. https://doi.org/10.1016/j.seizure.2008.08.007

[11] Xie, J.B. Video format inComputer teaching and application in life, Science \& Technology Information, 2008, vol. 32, pp. 562-563.

\section{Author}

Xiaopeng Jing is an associate professor in the School of Architecture, Chang'an University, Xi'an 710061, Shanxi, China (jingxp1207@163.com).

Article submitted 14 February 2017. Published as resubmitted by the authors 27 May 2017. 